\title{
An authentic feeling? Religious experience through Q\&A websites
}

Archive for the Psychology of Religion 2020, Vol. 42(2) 2II-23I

(C) The Author(s) 2020

Article reuse guidelines: sagepub.com/journals-permissions DOI: |0.1 |77/00846724209|745 | journals.sagepub.com/home/prj

\author{
Rosa Scardigno $(D$ and Giuseppe Mininni \\ University of Bari Aldo Moro, Italy
}

\begin{abstract}
As the "Sacred Place" - meant as the new space for religions offered by the Internet—demands for continuous investigations on the encounter between traditional narratives and social practices, the rapid growth of Question and Answering websites asks for improving social research about the Authenticity of the religious feeling as well as their responsibility in the construction of a shared knowledge. In this background, the aim of this study is to investigate the role of Q\&A websites as additional interpretative resources in accordance with different religious forms of life. About 800 extracts - composed by questions and answers-from the religious pages of Stack Exchange were analyzed, in accordance with social discursive psychology, through bottom-up and top-down pathways. In relation to the different emerging questioners' profiles, the rhetoric of "closeness" and "openness" reveal a dialectic trend of these websites in offering both supplementary and extending religious experiences.
\end{abstract}

\section{Keywords}

Authenticity, new media, Q\&A websites, religious feeling, rhetoric

\section{Introduction}

The focus of this work is on a new (discursive) space of the semio-sphere (Lotman, 1984) deriving from the meeting between the more and more embedded nature of the Internet in everyday practices and the same pervasiveness of religious "forms of life" (Belzen, 2005; Manuti et al., 2016) in subjective experience.

On the one side, new media - especially referring to social networks and Q\&A websites - have increasingly gained social value for several reasons. In particular, they act as primary resources for users to get help from peers as well as to put a person in touch with others with similar conditions, receiving emotional support and quick remedies (Bratucu et al., 2014; Kanthawala et al., 2016). On the other side, religions act as reservoirs of elements, stories, interpretations, prescriptions and verbal commandments (Belzen, 2010), concerning the meaning of life (Geertz, 1973), that legitimate themselves and assume the power to determine human experience and behaviors, especially thanks

\section{Corresponding author:}

Rosa Scardigno, Department of Educational Sciences, Psychology, Communication, University of Bari Aldo Moro, Via Crisanzio 42, 7012I Bari, Italy.

Email: rosa.scardigno@uniba.it 
to their narrative character. Since religions are intrinsically constructed as systems of meanings (Park, 2010) and as systems of communications (Pace, 2008), they can be no longer bound by institutional, communal or geographical settings (Lee, 2018). Indeed, in the more general predominance of media culture in all the domains of human life, also religious experience has been "mediatized," meaning that religious symbols and practices have been reshaped by the digital words (Hjarvard, 2011). In particular, the process of mediatization concerning religious field cannot be uniquely explained through a one-way and institutional directive; rather, it is the outcome of the interplay between top-down and bottom-up communication dynamics as well as of mutually conditioning media practices (Zeiler, 2019). These virtual flows take new challenges to both religious identities and religiosity - meant as the strict subjective feeling with religion and with the Transcendent — as they are set as alternative realities to be explored and retained (Dawson \& Cowan, 2004; Hadden \& Cowan, 2000), where both cognitive and emotional dimensions are at stake.

Therefore, the encounter between religions and the Internet demands for investigations about how the traditional narratives and social practices - typical of any religious systems of communication (Scardigno \& Mininni, 2013) - evolved and adapted to a "network" society (Campbell, 2012). The so constructed "Sacred place" (O’Leary, 1996) enhances new relations between reality and virtuality: whereas historically religions tried to present with a "real" language what belongs to a "metaphysic" world, nowadays the potentially unlimited world of Internet emphasizes the structuring of the "metaphysic" in a technological "physic" format (Pace, 2013). This new space is a part of the religious system of communication and is specifically set at its fourth level. Indeed, each religion was usually born from the impulse of the "Living Word" of the Savior (first level), that becomes "Given Word" when It begins to be preserved through the institutionalized memory of a System of Beliefs (second level). At the third level, through Sacred Texts, legitimate interpretations and structured communities, the Given Word crosses any space, time and generation borders. At the fourth one, the Given Word challenges itself taking the language of new media and experiencing so wide, complicated and differentiated contexts. In turn, this fourth level can have an impact on the memory of the original Living Word (ivi).

\section{How is Internet changing and how is it changing religions and religiosity?}

Web 2.0 is an umbrella term referring to sites, systems, and applications whose main feature is the possibility to generate and share content on the Web by users. Since early 2000s, it was defined as a new kind of Web no longer based on a network of hypertexts - as in Web 1.0 - but on a new "architecture of participation" (O'Reilly, 2007), since it improved co-production of information, social networking and rich user experiences (Barassi \& Treré, 2012). However, since across the last years the Web developed beyond the interactive processes of Web 2.0 in several ways, the concept of "user participation" gave way to a new keyword, "users' cooperation," which better identified Web 3.0 technologies (Fuchs, 2008). Actually, in spite of a linear understanding of Web developments, a more integrated approach was followed, since a new Web platform does not replace the previous one, rather their applications coexist in an integrated socio-technical system (Barassi \& Treré, 2012). Therefore, new paradigms of research pay attention to media as "practice" (Postill, 2010): in this point of view, human action is the starting point to study the structures emerging through recurring and significant interactions with technologies (Orlikowski, 2000). Among these ones, social networking became quickly prominent in the online world, since individuals have the opportunity to represent themselves, to manage personal virtual worlds, to articulate social interactions and so on. In the great variety of the proposed applications, functions and communication tools, social networking represents a must for most people around the world: this massive adoption 
is related to social, technological, informational and even educational factors, such as learning and sharing ideas and knowledge (Jan et al., 2015).

In the various scenario of social media, Q\&A communities are focused more on knowledge contribution and diffusion than on sharing information about individual news, moods, attitudes and so on. Indeed, they are usually formed and attended by strangers with the same interests, rather than by acquaintances. The dynamics of knowledge contribution and sharing typical of these communities can be explained through two main categories of motivations (cfr. Jin et al., 2015): organization-based and individual-based motivations. The first ones embrace organizational culture, climate and structure, and management support, rewards and incentives - for example, cultures emphasizing trust (Wang \& Noe, 2010) and innovation (Hsu, 2006) will promote knowledge sharing. The second ones take account of individual features - such as openness level and curiosityperceived benefits and costs, beliefs in knowledge ownership and justice.

More generally, the success of online Q\&A communities can be explained through two theories:

(a) The social capital perspective. Usually embedded in interpersonal relationships and networks, the social capital in social network is created through contacts, social ties, gratitude, respect, trust, and friendship that members construct and maintain (Wasko \& Faraj, 2005).

(b) The social exchange theory. Opposing to economic rewards, benefits from social exchanges - usually enhancing feelings of belonging, gratitude, trust, and loyalty — specifically deal with obtaining knowledge and receiving attention (Lanham, 2006).

In sum, if compared with other types, Q\&A communities expand regular Q\&A systems with social networking features, improving social linkages among users, questions and topics (Jin et al., 2015). Among the several consequences, these new systems and practices enabled designers and users to deeply reorganize traditional models of social dynamics, such as authorship, authority, access, retrieval, and relevance (Gazan, 2011).

Across the last years and the several research domains, scholars investigated the ways the Internet is managing and changing both the religious institutions and the more subjective religious experiences (Campbell, 2012; Hackett, 2006). These emerging reflections represented the efforts to answer to several questions concerning what is "new" about the perceptions of the (religious) feelings, reality, identity, social patterns and community building related to the Internet. Notwithstanding their variety, these positioning were organized in two main directions.

On the one side, new spaces of confidences were offered to the believers. Challenging and overcoming the prevailing notion that the Internet is mainly about communication and information, it really acts as a multi-functional tool (Hackett, 2006). Therefore, the "netizens" can discover a great range of opportunities: (a) proposals of conversion - even sometimes in increasingly aggressive ways (Cowan, 2004); (b) wider chances for learning and seeking, empowering the "personal autonomy"-also thanks to previously inaccessible Sacred Texts and secondary materials (Gunther et al., 2000; Hoover, 2003); (c) additional possibilities for spiritual or religious experience and practice, especially for certain alienated social categories. In particular, these ones can also benefit from advocating discourses and dynamics of international human rights and trying to bypass any kind of political, cultural or religious exclusion; and (d) finally, cures for sickness, solutions and answers to spiritual or practical problems.

In addition, concerning the more subjective religious engagement and interactions (Campbell, 2012), cyber-believers can experience a greater flexibility in religious practices and a more personalized access. Moreover, the online participation enables members of virtual communities to engage in new social and discursive opportunities, such as debates on beliefs, policy, habits, in a 
way that is often not possible offline. Nonetheless, in the online-offline interactions, the online experience can represent a "supplement, not substitute" for offline involvement (Campbell, 2005).

On the other side, the nature and dynamics of World Wide Web challenge several religious traditional "core concepts," creating new spaces for uncertainty and less reality-anchored feelings (Campbell, 2012). First, taking into account the Internet's ability to create positions of power outside the traditional structures, there is a rise of "instant experts" (Berger \& Ezzy, 2004), legitimated through their (only perceived) expertise. Second, the Sacred space, time and rituals are effectively dematerialized: it is not easy to separate online religious and non-religious activities, since the choice of the devoted time and space to dedicate is made by the same net-believer (Vecoli, 2013). Therefore, the religious feeling is also affected by the breakdown of traditional religious communities, as they risk to be constructed through loosely bounded social networks.

Additional comes toward a "looser" religiosity are related to more general factors: the online world presents the widest level of complexity and differentiation; as such, it can't be completely supervised by any religious system. In other words, the meanings traditionally offered by welldefined Systems of Meanings have to face with more variable significances offered by this social context. The result is the "risk of sense," that can result in the multiplication and the enlargement of the (already polysemic) sense typical of the religious world (Pace, 2013).

Overall, the Sacred cyberspace offers the opportunity to satisfy specific relational and informational needs as well as the possibilities to build and present new facets of religious identity. On the other side, it undermines the same pinnacles of religious organizations and practices; consequently, the new possibilities for religious identity can reverse in its fragmentation too.

\section{A critical feature: Authenticity}

In this balance between living new opportunities and facing with more uncertain experiences, between the risk of "disembodiment" and a complete "virtual embodiment" (Ajana, 2005) concerning religious domain, what is really at stake is the "Authenticity" of the religious feeling. Several scholars emphasized the cultural rooting of the ideal of Authenticity in relation to "processes of modernity, secularization, new constellations of social life, and evolving understandings of the self" (Whitehead, 2015, p. 125). Although it encompasses a variety of meanings, two main different explanations of Authenticity were offered (Lindholm, 2008): (a) claim for uncontaminated or legitimate origins and (b) presumed correspondence of representation and reality.

A more popular and social media oriented expression focused on Authenticity as the subjective possibility to realize one's own humanity: the claim to "be real"/"be true to yourself" is in line with an "expressive individualism," the rejection of traditional authorities and the searching for experiences in opposition to conformity (Taylor, 2007). Whereas some define Authenticity in terms of face-to-face participation, others believe it rather concerns the adherence to the core values of (sub) cultures (Williams \& Copes, 2005): both in face-to-face and in online contexts, participants can construct, negotiate and defend boundaries of their (sub)cultures; in addition, people are available to just share online stories that might not otherwise be told with others they likely will never meet face-to-face.

As for the more specific religious domain, since religions became part of the market culture, they were subject of suspicions and uncertainties also related to the "publication by the masses" (Miller, 2009, p. 9) and the consequent agency and authorship explosion. Moreover, the functioning of social media produced new forms of religious expressions, practices, and communities. This means that religious Authenticity should no more be defined as a "question of correspondence but rather of generativity" (Whitehead, 2015, p. 127), since it is related to the online practice and community formation done in the complex scenario of social networks, blogs and so on. 
Several scholars emphasized Authenticity as a core concept in online religious domain (Tan Meng, 2019), highlighting the variety of possibility of online participation as well as its pros and cons. For example, in the domain of virtual pilgrimages, even if it cannot realize the same connections to sacred locations or to other pilgrims as in reality, participants can live significant and transformative experiences: connective technology can help the cyber-pilgrims to both escape the profane and enter into a sacred atmosphere as well as to connect with God, rather than with a place or an event (Hill-Smith, 2011).

More generally, social research about online Church emphasized the role of "familiarity" as a key factor for Authenticity for several reasons (Hutchings, 2010): (a) it creates a more "real" environment, simulating some features of local attendance; (b) persons can be assured of the theological validity of the online ministry, as they participate through expected structures and styles; and (c) it acts as an attracting strategy for outsiders. On the other side, likewise perceived "absurd" elements can conflict with the Authenticity (ivi): (a) users participate and interact in a "synthetic" environment, and this can be experienced as an obstacle to a true sense of immersion and (b) prevailing moods of online communication are mostly founded on flippancy and irony, which can be perceived as opposed to a sense of sacredness.

In this so complex scenario, since "digital religions" (Campbell, 2013) can have real world impacts on participants and/or observers, a core question about authenticity concerns how "the relationship between the offline and online body can be defined, and whether online bodily experiences can be judged to be as authentic as offline experiences" (Radde-Antweiler, 2013, p. 93).

A possible answer to this question comes from the following considerations: since religions are always religions-in-action, therefore social research should focus on "lived religion," that "is not about practice rather than ideas, but about ideas, gestures, imaginings, all as media of engagement with the world" (Orsi, 2003, p. 172). This means that, on one side, lived religion is not separated from either important or everyday life things; on the other side, sacred space is not isolated from other cultural domains, discursive practices and from the places where these things and the relative relations are constructed. In this deep cultural anchorage of lived religion, an essential matter about its Authenticity concerns the use of religious idioms and the construction of worlds through them that, at their turn, shape the believers' worlds (ivi). Therefore, a central issue of lived religion is on social agents/actors as they narrate, interpret and reconstruct their experiences.

This means that, in line with believers' perspective, as in real world there is no separation between "religious" and "non-religious" domains, in the same way, in the religious realm there should be no separation between "offline" and "online" life and experiences. Since the Internet acts as an extension of the social world, it can work in the same way in domain of lived religion: it is an extended environment where people "do" religious practices and experiences through words. The last reflections are an essential input to overcome the traditional distinction between "religion online" and "online religion" (cfr. Helland, 2005), whose difference can synthetically presented as follow: the first websites seem to provide only religious information and not interaction, whereas in the second ones people can act with unrestricted freedom and a high level of interactivity.

Making a step forward means to recognize that, on the one side, there are many examples of religious websites where information and participation conjoin (Young, 2004) and, on the other side, that there is a variety of forms of religious participation and interactions available to those who surf the net. Therefore, in accordance with the strictly subjective nature of religious experience, it is hard to determine if certain online activities are religious ones or not.

For example, is the act of reading religious scriptures from a website a religious one? Several reasons can support positive, negative, as well as "it depends" answers. A more complicated question: is participating to new forms of religious websites, such as questions and answers websites (Q\&A), a religious act? 
Possible answers to these questions derive from focusing upon the participants' perception, their subjective interpretations and, especially, their discursive participation. As studies about rituals recognize (Jennings, 1982), it is not the mere action that makes an activity a religious one, rather it is the intent behind the action that gives it a religious significance. For example, lighting a candle may or may not be considered a religious event; it is dependent upon the situation and the participants' interpretation. The same holds true for clicking hyperlinks as well as for writing, questioning, answering and commenting on websites. In other words, social research about Authenticity in online religious experience should take into account this practice as a type of religious discursive practice, as participants can say something that is actually an action, and they can do something while they are just writing/chatting.

Across the several investigated domains, the mediated interactions in Q\&A websites recall, on the one side, the asymmetric nature of communications - anyone asking for something occupies a "down" position with reference to the "up" position of the answerer-and, on the other side, the efforts for symmetry typical of the "social presence" (Riva, 2008) of the web 2.0. This interplay can have an interesting nature when the issues "at stake" have to do with cultural and subjective domains, such as religiosity: persons search for suggestions about how to comprehend and to behave, founding suggestions in the "wisdom of many" (Bratucu et al., 2014). Several factors can explain the preference for Q\&A sites to social networking sites (Morris et al., 2010): first, questions can be mostly posted anonymously (or under a pseudonym); second, the audience of potential answerers consists of an entire community; finally, many Q\&A have no limits for message length, so much longer, more detailed questions to be posted.

\section{The research}

\section{Aims}

In the light of this complex background, the overall aim of this work is to investigate the specific features of Q\&A websites making them an opportunity to deal with religious feelings and contents and to co-construct shared knowledge, both for those who feel the need to "question" and for those who are committed in "answering." Social Q\&A are sites (or services) requiring (Shah et al., 2009): (a) a method for users to present an information need in the form of a natural language question; (b) a forum for public responses and, eventually, comments; and (c) a community, based on participation level, in which the above transactions are embedded.

We believe that these particular websites act as typical religious discursive sites: the dialogical turns - made of questions, answers and comments - are especially consistent with the same nature of religions, which are founded in the human need to pose questions about the "Transcendent" and in the human hope for answers about the sense of life.

Therefore, we want to study the opportunities and dynamics of co-construction of contents and knowledge, in the context of Q\&A websites, as related to religious contents, with particular focus on the different levels of Authenticity coming from the social participation and the discursive interactions. Our main research question has to do with the needs at the basis of the questioners' attitude of searching for specific contents in this context, rather than in offline/other ones, as well as the motivations and efforts to construct knowledge from the answerers' side. In line with the literature about Authenticity and in the light of our aims, we proposed a double-faceted perspective on Authenticity: the first one is related to the more traditional correspondence with legitimate origins; the second one to the context of social media, where "authority" and "generativity" are core concepts to better comprehend religions are "lived" in Q\&A websites. A particular emphasis is devoted to the Authenticity of this kind of participation: studies on high levels of online self-disclosure focused on the 
psychological effects on anonymity, since what is controversial or embarrassing can be seek and spread without losing privacy and both online and offline reputation (Joinson \& Paine, 2007; Sobel, 2000). Therefore, we suppose that these kinds of website offer specialized additional discursive interpretative resources that involve both persons and communities to discursively construct and modulate their private and public positioning in accordance with the different religious feelings, roots, habits, values and so on. In accordance with the theory of the dialogical self (Hermans, 2002), we believe that the Authenticity and responsibility experienced by the virtual questioners and answerers are expressed through a variety of dialoguing claims and dialectical positioning.

In line with the nature of religious contents as well as with the specific features of Q\&A websites, we hypothesized that

(a) Questioners authentically participate by constructing queries not only through a searching attitude for definite pinnacles and legitimate anchorages, but also through requests going "beyond" these findings, following their "exceeding" needs;

(b) Complementarily, answerers authentically participate by constructing responses through legitimation practices coming from either religious traditions and texts - the "correspondence" side - or more subjective experiences and knowledge - the "generative" side of Authenticity;

(c) Since the Internet offers extended opportunities to experience the "lived religion," the efforts for Authenticity proposed by different religious forms of life referred to their "classical styles"-argumentations, values, figures and so on-offering distinctive ways-ofbeing-in-the-world (Geertz, 2005). Nonetheless, these contents could be expressed through a shifting modulation between well-defined and shading claims.

\section{Procedure and data}

We selected about 800 extracts-Q\&A-from Stack Exchange (https://stackexchange.com/sites), a well-structured Q\&A website. It is a very popular web platform composed by about 100 websites, where a significant fraction of the participants constructing focused communities has deep expertise in the domain area and where "personal reputation" (constructed by the peer votes) represents a value, since it enables them to be rewarded and to gain new opportunities for participation (Anderson et al., 2012). This feature works as a guarantee for a good quality of answers, meant as "common good."

For each religious site-in particular from the webpages devoted to Christianity, Islam, Buddhism and Hinduism - we clicked on the link "top questions," where the highest up-voted discussions were classified. From the whole corpus of discussions, which represented our "population," we selected topics dealing with practices, habits and contemporary issues, such as abortion, homosexuality, suicide, polygamy, sexuality, drawing, music, Internet piracy, killing (insects), love, drinking, begging, vegetarianism, and footwear. We chose the five more up-voted questions from each webpage. The selected topics also had a "flagged" answer, meaning that the questioner found a favorite one and that, consequently, the discussion was almost over. All the available answers for each question when the research was carried on ${ }^{1}$ were part of our sample. This means that each questions had an average of 39 answers.

\section{Analytical procedures}

The extracts were analyzed in line social discursive psychology (Edward \& Potter, 2005; Harré \& Gillet, 1994), which emphasizes the role of discourses as social practices as well as the importance 
of symbolic artifacts - languages, rituals, relations - inside specific groups in order to better comprehend their cultures. These social and discursive dynamics are relevant both in the analysis of virtual communities and in the individuation of different profiles of cyber-believers which express emotions, needs, beliefs and desires thanks to their (discursive) participation to social media.

We applied a particular kind of discourse analysis (DA) known as "diatextual analysis" (cfr. Mininni et al., 2014). In particular, we made use of several interpretative tools, which had two main orientations (Scardigno et al., 2019; Zagaria et al., 2018):

1. Bottom-up pathways, through psycho-semiotic and psycho-stylistic markers aimed to reveal tracks of discursive modulation (Caffi, 2013) and subjective commitment acted by the enunciators. As for this last dimension, we particularly focused on agentivity markersany textual unit showing if the enunciator is source or goal of action-affectivity markers - any textual unit highlighting the emotional dimension of texts - embrayage/debrayage markers - any textual unit revealing whether the enunciator is involved or not.

2. Top-down reading of the texts, thanks to the "social-epistemic rhetoric" (Berlin, 1993), that is a construction capable of catching sense perspectives valid for particular groups of positioning. In particular, since rhetoric can be defined as "description of reality through language" (Cherwitz \& Hikins, 1986), then the social-epistemic rhetoric can be a fruitful devise to gain forms of knowledge constructed in specific communities.

\section{Main results}

\section{The "authentic" construction of questions}

The most upvoted questions concern a wide variety of matters, ranging from traditional foundations of the religious forms of life to more actual and pragmatic issues, such as abortion, possibility of killing insects, homosexuality and menstruation. Nonetheless the hard "polarization" and the peculiarity of some topics, throughout the involved religions we found several discursive and argumentative strategies that work as interpretative repertoires of an authentic religious feeling:

1. The anchorage to religious Sacred Texts. In turn, this attitude is double faceted: on the one side, quotations and religious pinnacles are set as preconditions for questions:

Ex 1: In Exodus 21:10 and Deuteronomy 21:15-16 (among many other passages), it talks about polygamy as if it were acceptable. $(\mathrm{C})^{2}$

Most of time, exact and accurate references are set as foundations for questioning (ex. 1), but also more mitigated and less precise claims are used, as in the example "The first precept goes something similar..."(B).

On the other side, questioners clearly ask for supported by quotations answers:

Ex. 2: What is the biblical basis for the claim that abortion is immoral? (C)

What are the specific Quran verses or hadiths that support this view? (I)

Please give some authentic quotes for the answers $(\mathrm{H})$

In the above examples, the direct and assertive style of questions as well as the qualitative adjectives "specific" and "authentic" testify the real will to get the required answers precisely. Therefore, 
the anchorage to Sacred Texts represents both the starting point of the "need for questions" and the required destination of the "need for answers."

2. The efforts of comprehension for some religious practices going beyond Sacred Texts. As, most of times, questions have to do with behaviors, attitudes and practices, questioners are not only interested with the religious foundations, but rather with the motivations and what's "behind" specific habits:

Ex 3: Are there any other, religious reasons for this? (H)

The words "reasons" and "reasoning," often used in the final sentences - which represent the real core of questions - express the authentic intention to gain a wider comprehension about the focused religious contents. This attitude acts as a typical feature of an "intrinsic" religious feeling (cfr. Allport \& Ross, 1967).

The efforts for comprehension can be also constructed in a more simplified way, for example, by direct oppositions:

Ex 4: Is listening to Music Halal (permissible) or Haram (prohibited) in Islam? (I)

In accordance with the dilemmatic nature of human mind and argumentations (Billig, 1987), as well as making use of the typical lemmas of the "religionese"3 (Manuti et al., 2016), the need for comprehension can be discursively constructed through the opposition between what is "allowed" and "forbidden," especially in the Islamic website;

3. The references to personal experiences. This feature is twofold too, as it concerns both strict religious experiences and more subjective/private ones.

In the first case, several personal beliefs and attitudes are presented, by the means of epistemic verbs concerning a cognitive domain-such as "I believe that . .." "I know in other faiths ...." "I am aware that . ..," "Well, I think . .."- as well as both active and passive experience verbssuch as "I have heard a session ....," 'We are told that ...' 'I've been told that ...' These expressions take the function to present oneself as an "offline believer" and as a member of offline communities. The complex and almost paradoxical encounter between what is "known" and what is "experienced" emphasizes the subjective feeling of "confusion" that works as a profound motivation for asking (ex. "Later on, a thought came to me which confused me . .." (H), "Now I am confused" (I)).

Very emotionally connoted sentences characterize the presentation of more subjective/private experiences:

Ex. 5: I've accepted the fact that I'm gay, however it's now making me question my religion. [. . .] I've recently read the Qur'an in English and the things that happen to gay people after death has put me into depression. I just don't see the point in praying anymore when I know I'm going to burn in hell for something Allah has burdened me with. (I)

In this excerpt, a private question is set as the basis of a religious crises, that is constructed through an ascendant climax, involving, at first, "questioning" and "depressive" attitudes and then a more pathemic narration, by the means of the metaphors of the "burn in hell" and of the "burden." 


\section{The "responsible" construction of answers}

When Internet users are committed in answering, we always found religious-anchored discursive constructions. Nonetheless, the different styles of answers act as discursive efforts for meanings in accordance with the interpretative repertories of the "responsibility," which works as the dialogical complementary counterpart of the "authentic" religious feeling.

Christianity. In the Christian website, answers are organized in line with the following main directions:

1. The reference to Sacred Texts, above all the Bible:

Ex 6: If we accept the beliefs expressed in the early Church that abortion is murder, as the Fathers suggest, then the Mosaic commandment against murder (Exodus 20:13), re-emphasized by Christ (Matthew 19:18, Mark 10:19, Luke 18:20), should serve as an adequate biblical basis . . .

This attitude, which is widely expected in accordance with questions - often clearly asking for references - is not discursively constructed as a mere "quotation list." Rather, references are part of wider argumentations and reveal the answerers' religious competences in supporting their claims and in offering contextualized anchorages, as in the following example:

Ex. 7: Because it was based on cultural conditions that no longer exist in the Christian world, the prohibition against men having sex with men in Leviticus 18:22 and 20:13 is one of many Old Testament laws that no longer apply to Christians.

2. Made-up religious contents. Sometimes, answers are constructed as a kind of "online catechesis."

Ex. 8: Do you not know that Jesus came to this earth to live, suffer and die for you? Then should you not live and, if needed, suffer and die for Him too? We are meant to be vessels of God, fit for his work.

In the above excerpt, the enunciator takes an interlocutory attitude: the two rhetoric questions, directly involving the other, are based on the same repeated ascendant climax - "to live, suffer and die" - and are followed by an equally rhetoric answer, founded on the first plural person and on the metaphor of the "vessel";

3. Attempts for more personalized argumentations.

Ex. 9: If "some" includes me, I can give you my answer. I consider myself Christian [. . .] I don't look [. . .] I do think [. . .] I don't think [. . .] and I don't look [. . .]. Somewhere in the new testament it says something like "the law is written in your heart." I happen to agree with that.

In 9, the answer's protagonist is "I": most of sentences are set at the first singular person, that is subject of both positive and negative, both cognitive and active verbs. Therefore, the subjective position is discursively constructed through an assertive style, in opposition with the vaguer references to the Sacred Text — 'somewhere' and 'something like';

4. The will to exceed the strict religious boundaries. Answers are often set at the interception among religious contents, cultural-historical domains, scientific foundations, logic argumentations and so on. 
Ex. 10: Many organizations, including many Christian organizations, have tried and failed to change homosexuals into heterosexuals through prayer, repentance, therapy, including Skinnerian aversion therapy, and various other methods.

In the above example, religious "methods"-prayer and repentance - act as seamless supporters of more scientific ones. This attitude can also lead to more polarized claims, as in the following example:

Ex. 11: Take religion out of the debate completely, and the science says that a fetus is both fully human and separate from the mother.

where the ancestral duality between science and faith is overcome through the provocative assertion of science as substituting, rather than mere supporting, religious thesis. The relationship between Science and Faith is part of a more general discussion about the continuity between religious and non-religious world. This means that laws, rules, science, can support religion claims and vice versa.

Beyond the contents, as for the more argumentative domain, we found a great variety of strategies, ranging from strict logical argumentation - through comparisons, deductions, "if-then" periods - to more rhetoric repetitions of key expressions (e.g. "he created one man and one woman [. . .] one man and one woman"). In addition, answers are well-organized texts, also thanks to metadiscoursive index and space-time contextualization. All these strategies reveal on the one side the personal and committed participation in answering and, on the other side, the desire of acceptance of one's own claim as trustworthy and credible.

Islam. In the Islamic website, several discursive strategies converge in more categorized and simplified argumentations. In line with the Christian domain, most of time the answerers make use of quotations and Sacred references in order to legitimize and empower their claims. Beyond this expected feature, a repeated argumentative strategy is the opposition, invoking the Islamic "religionese," between what is "allowed" and "forbidden." For example, in answering to a question about music, one participant creates two separate sections, respectively, entitled "Music is Haram" and "Music is Halal." This strategy is used even if questions do not explicitly ask for this.

Most of times, contents are expressed in basic ways, as in the following example:

Ex. 12: As far as I know the things that harm your body or mind or man as being Muslim is haram. If you hear music you are harming your ear, i.e.; you are harming your body.

More generally, the efforts for a "secure" argumentation are accompanied by attempts to construct a solid feeling of community. This direction is acted by

1. Typical religious invocations, such as "Almighty knows best" and "Allah knows best," and first plural persons subjects (e.g. "we Muslim”);

2. Made-up (also interreligious) contents, such as in the example "No matter how hard it might be, remember that 'Allah does not burden a soul with more than it can bear'," where the interpersonal attitude also works as a direct call for the other;

3. The rhetoric of "brotherhood," as we found in the example "Salam Brother Curious," where a feeling of welcome and empathy is emphasized, also through the typical Arabic greeting.

Notwithstanding the main tendency to offer structured and well-defined argumentations, several additional strategies emphasize the inevitability of more composite answers. This attitude is constructed through 
1. The efforts to go beyond the opposition between "Haram" and "Halal":

Ex. 13: If it is not apparent that something is haram, one should try to determine what is haram and halal in terms of moderation (and not be an extremist or to take every situation too lightly).

In several answers, the call for "moderation" (ex. 13), "safety" and "opportunity" is set as a general guideline to avoid extreme and polarized positions;

2. The claim for wise interpretations:

Ex. 14: Yes that's true. But men shouldn't take it literally. There must be kindness and understanding. Islam ordered the husband to be nice and gentle and understanding.

The religious principles - in the ex. 14 concerning sexual behaviors between husbands and wives - are affirmed in an assertive way (first sentence), mitigated through the second adversative sentence and better explained in the last part of the example, even if "hard" verbs ("must" and "order") are used;

3. The variety of argumentations and counter-argumentations:

Ex. 15: This is a complicated and messy subject. I will try to be as objective as I can at my answer, in summary I will mention three different opinions along with their proofs.

Most of times, answers are structured in multiple sections, each of one claiming for a - usually well-argued - thesis. The difficulty to take a unique and definite answer can lead toward open ends too, as in the example "The question that needs asking is whether whenever an image is made should it be taken that it must be for idolatry; and if not, then by what do we distinguish?," where the answer paradoxically ends with another question.

Buddhism. In the website devoted to Buddhism, answers are organized in accordance with a double feature: on the one side, Buddhism is presented as a holistic "form of life." In this case, claims are legitimated through the reference to principles, values and laws of the Buddhist world:

Ex. 16: It makes sense to try to understand the spirit of the precepts, rather than the letter only. The precepts are not the arbitrary will of Buddha. They have a function. They protect us from bad karma.

In 16, as in many other cases, the general aims of the Buddhist beliefs, practice and values are recalled. They both improve and emphasize the pinnacles of the system of beliefs, exceeding the more specific questioned topics, also through the typical "religionese" (e.g. the reference to the "karma"). In addition, in this encompassing way to present Buddhism, a lexicon recalling the educational domain is mostly used, as in the example "In the teachings of Thich Nhat Hanh, the precepts are trainings, not commandments."

In this frame, answers can also assume a more philanthropic lexicon and domain, founded on cultural and human made-up contents and on exhortations, as in the following example:

Ex. 17: What we see in the world, it reflects our own minds and hearts. If you want to see more love in the world . . . then give to beggars and love all unconditionally, regardless of how they treat you! 
In order to better explain some core concepts, a dialectic argumentation is used too. Anyway, in this case, the opposition is not between "allowed" and "forbidden," rather it is founded on values:

Ex.18: But people who are devoted Buddhists can develop into very genuinely selfless and compassionate beings and whether or not you believe in karma and rebirth, the world could use more selflessness and compassion and less craving and entitlement.

Positive subjective and interpersonal values are posed at the basis of about all answers, as an overall way of being that is strictly opposed to negative values, represented by the key metaphor of the "poison."

On the other side, the variety of the Buddhist traditions is emphasized. As such, concerning specific topics, answers present the several positioning, as in case of "love:"

Ex.19: It depends which Buddhism we are talking about: Both Theravada and Mahayana, including Zen, would consider romantic love a kind of pathological obsession. In Vajrayana schools though, emotions, including romantic love, are considered a form of energy [. . .].

The verbs "to depend" and "to consider," as well as the expressions "a kind of," "a form of," take the function to "mitigate" the enunciative strength of the claims and to emphasize any possible interpretative pathway. This variety can lead, in some cases, even to opposite answers (ex. 20 and 21):

Ex. 20: Even if killing a single mosquito would end all cases of malaria in the world for ever, the (Theravada) Buddhist philosophy would be to abstain from killing the mosquito.

Ex. 21: In light of the above, the no-killing rule should not be understood literally, as an absolute law, but as a guideline for training the mind.

Overall, a more dialectic atmosphere characterizes the Buddhist website, where a more explicit awareness of the dialogic and dilemmatic nature of religious positioning and feelings was found, even if in the overarching frame of general precepts, principles and values.

Hindu. Also in the religious site of Hindu, responsible answers fully draw from religious scenarios, Sacred Texts and figures, meanings and traditions and make use of the "religionese."

A first tendency acted by net-users is the recall of the founding pinnacles. Therefore, some answers start with assertive, declarative sentences having an ontological and constitutive nature:

Ex. 22: Hinduism does not deal with social situations like Western religions do.

This kind of premise introduces the reader in the religious world, through both the specific Hindu connotations and direct/indirect comparisons with other forms of life.

In the efforts to define the Hindu world in specific ways, we found two main tendencies. On the one side, answers are founded on the core concepts of Hindu:

(a) The spiritual emphasis, which include concepts such as "soul" as well as the attribution of intelligence and feelings to animals and vegetables.

Ex. 23: As the soul transmigrates through 8.4 million species, some species are progressive (prepare the soul for more freedom in higher species) and some are regressive (limit the freedom due to bad qualities). 
(b) The hierarchical organization of living (both animal and human) beings.

Ex. 24: Within Hinduism, Ritual Purity is understood to occur at many hierarchies. The Gods (and deities) exist at the highest level of purity. The Priests who tend to them must exist at a similar level of purity [. . .].

(c) The seamless relation between religious world and other life domains.

Ex. 25: Meat-eating destroys mercy, as a result the human society degrades into a flock of 2-legged animals. Meat-eating is also the principal cause of all the wars, because it cultivates hatred. The amassed hatred needs some escape, therefore it erupts into the wars.

On the other side, in order to better explain some concepts, again net-answerers make use of a dialectic argumentation.

Ex. 26: The practice of separating menstruating women from the household is based in the concept of Ritual Purity \& Ritual Contamination in the Vedic tradition. Ritual Purity and its understanding is a major aspect of any religious tradition. At its heart, there is a belief that humans exist in a natural state of uncleanliness, and this 'uncleanness' is not just physical, but spiritual as well. Any emanation from the body is considered unclean.

In this case, the opposition concerns "purity" versus "contamination," "clear" versus "dirty," involving both physical and spiritual conditions. These oppositions are used to explain several matters, such as male/female behaviors as well as everyday practices, such as the possibility to wear shoes in the church.

\section{Discussion}

Religious feelings, beliefs and belonging are founded on "a process, a search for significance in ways related to the sacred" (Pargament, 1997, p. 32). This search can be acted through the several efforts to find some forms of certitudes and certainties (Mininni et al., 2014; Scardigno \& Mininni, 2014) which can construct both subjective and collective pathways of meanings. This process can start through the discursive practices and, in particular, through the dialogical act par excellence, that is "questioning."

The "cultural turn" in religious studies, focusing on religious discourse, challenged the systematic scientific surveys since the 1960s: the work of Bellah (1970a), Berger (1967), Douglas (1966), Geertz (1973), and Thomas Luckmann (1970) was a warning to take seriously religious symbols, rituals and their meanings, as well as ordinary conversation, in constructing and maintaining the plausibility of everyday reality (Wuthnow, 2011). Whereas Geertz (2005) emphasized the importance of "meaning" in religiosity — as (a) expressed by "saying," (b) materially embodied and used and (c) related to "ultimate" concerns - Douglas $(1966,1970)$ offered a more systematic approach. She focused on the relationship between social form and religious expression, since social structure and group pressures can predict and justify the patterns of a specific society. Therefore, high/low levels of structure and pressure should lead toward either more strictly defined boundaries or more idiosyncratic and inclusive cosmology (Bowie, 2006). In this background, the Authenticity of religiosity in virtual experience can be investigated through the discursive co-construction of contents and the online social interactions, concerning different religious forms of live, in the shared efforts of offering both close to the origins and generative forms of lived religions (Orsi, 2003). 
In our data, nonetheless embedded in their religious and cultural roots as well as the variety of the involved topics, questions exhibit some common features, mainly deriving from their motivations. In accordance with the theory of the dialogical self, as well as with the discourse analysis frame, we can find three main "questioners profiles":

1. The searchers-for-online-confirmations. Sometimes, even if believers know and agree with some religious pinnacles, they express the need to find the precise quote in the Sacred Texts talking about that principle. This attitude testifies the importance of the original source as one of the main foundations of the religious feeling;

2. The offline-unsatisfied-believers. This positioning is particularly close to persons experiencing a "confused" feeling, deriving from some incongruence between subjective experiences and religious claims. In this case, questions are constructed through more pathemic and embrayage argumentative strategies;

3. The searchers-for-online-deepening. Usually this position belongs to those who ask for reasons, reasoning and categories at the basis of some practices, behaviors and habits. In this case, it is not essential "who" says something, rather "why" and "how" something is claimed. This means the predisposition toward a more "intrinsic" religious feeling.

This means that their searching-for-Authenticity attitude in the domain of Q\&A websites is not just satisfied through defined contents and original legitimation, rather it has to take into account the "exceeding needs," typical of the religious searching for meanings (Geertz, 1973).

As for the discursive construction of questions, most of time "sharpened" modalities to present one's position and contents are used (e.g. "Note: I know this may start a firestorm, so I will be careful here" (C); "a certain interpretation of the 5th precept" (B)). Since in offline contexts "mitigation" - meant as a kind of discursive modulation - is usually aimed at "saving the face" in the interpersonal turns, in the online and anonym contexts its object is to save both the web and the religious reputation, as it avoids that questions can be censured. The same function is acted by the proposal of multiple positioning, including the personal ones, at the basis of the final request. In this line, less usual is the use of strict and polarized expressions, as it could be at risk of "closure" by the website moderator - as explained in the netiquette of the website.

As for the answers, the discourse analysis conducted on our data reveal several discursive cues, argumentative strategies and interpretative repertoires which encompass the variety of the positioning in accordance with the specific traditions, Sacred Texts, interpretative baggage related to so encompassing "forms of life." Also in the domain of Q\&A, the Authentic construction of religious contents follows the "classical styles" typical of each religious form of life, in line with their distinctive ways-of-being-in-the-world.

Beyond the religious pinnacles and shades, we found two opposite social epistemic rhetoric that work as guidelines in the construction of answers: the "closeness" and the "openness." These rhetoric are coexistent in each analyzed religious website, but they can be prevalent in one or more of them as well as can be balanced in accordance with the typology of questions.

In their strives to authentically and responsibly answer to questions, participants legitimate their positions and claims through the references to Sacred Texts, principles, values and traditions, offering simplified argumentation and unique directions. As such, the rhetoric of "closeness" supports the claim that online religiosity represents a "supplement, not substitute" (Campbell, 2005) with reference to the offline commitment and feeling.

On the other side, more "opened" rhetoric are set on multifaceted claims, positioning and interpretations, as well as on the dilemmatic nature of argumentation, founded on both logoi-antilogoi opposition and on the reference to the "other" - that is other positions, religions, life domains, and 
so on. This rhetoric confirms the metaphor of online religions as an "extending compass" (Pace, 2013): the religious feeling can be cultivated also thanks to the new space offered to the (old) need for answers about (contemporary) issues.

The so co-constructed religious answers, founded on "close" contents as well as on necessary "open" positioning, testify the role of new media as supporting the "fourth level" of the religious systems of communication (ivi). This means that religions positively face the challenge with the complicated and differentiated world of new media and, in the more general "System of Communication," may have an impact on the memory of the original Living Word.

Beyond the exposed matters, cyber-believers can find additional sources for meanings at a more interpersonal level:

Ex. 27: A wide variety of scripture can be cited in obvious support of abortion (as an act of murder) is inherently immoral. (C)

Ex. 28: Please do not give up brother, I wish the best for you [. . .]. (I)

Ex. 29: I'll pray for you too inshaAllah. (I)

Metadiscursive index and sentences create different relational scenarios, which can be set at different points of a continuum. At the one pole, we found an asymmetric attitude, in line with the top-down relational position, typically attributed to the questioner-answerer interactions, as in the ex. 27, where the adjective "obvious" and the adverb "inherently" emphasize that the answer is set on a higher level. On the other pole, a more symmetrical and informal "care" about not only the other's request, but especially about the other as a whole is set. In ex. 28 and ex. 29, the references to wishes and prayers and the handle "brother" work as a supporting discursive act and as a virtual embrace. This level enables questioners to feel that through Q\&A websites they can find not only "answers," but even a comprehensive community.

This investigation about the discursive engagement for Authenticity and responsibility in the online dynamics of Q\&A represents another answer to the main fear concerning online religious experience, which is the belief that religious "disembodied" practices are in essence inauthentic (Campbell, 2004). In the same way, the Internet can be useful to maintain existing offline communities through online interactions, it offers alternative kinds of community. In this case, the Authenticity cannot be set through the "familiarity" of practices, rather through the discursive efforts to guarantee anchorage to religious traditions and, at the same time, to offer additional contents. This can happen in the discursive sphere guaranteed by the web reputation and all the online social dynamics, in a new balance between the "Networked Individualism"- the promotion of the individual action- and the "Networks of Control"- - the encouraged control over interactions (ivi, 93-94).

\section{Conclusion}

Since both new media and religious systems are important cultural intermediations in providing pathways for meanings and subjective feelings, the several forms of interaction between media and religion represent important and challenging issues for social research (Martin-Barbero, 1997). On the one side, media act as informing, recording, sharing and distributing symbols tools; on the other side, religions represent the symbolic form for diverse methods of comprehension, understanding and experience (Mohammadi, 2003).

The several interactive processes of Web (2.0 and 3.0), focused on users' participation and cooperation, offer more and more updated opportunities in experiencing new pathways of "lived 
religion" as well as in the formation of online communities. Nonetheless, the risks related to deception, trust and suspicion, belief and doubt, intrinsic to social media, make the rhetoric of Authenticity essential with the Internet users' practices of interpretation and discernment (Whitehead, 2015). Among social media, at the interception of the old certainties of religion online and the new challenges posed by online religions, Q\&A websites represent a way to make extended, new and unique the founding process of construction of reality, that is the dialogic questioning/answering turns. Therefore, these websites are an interesting type of discursive religious website, since the Authenticity of lived religions finds extended and new challenges.

In our research, an Authentic religious feeling is discursively constructed in complex and dialogical ways: as for questions, the anchorage to religious Sacred Texts, the need for a deeper comprehension and the necessity to simplify an "exceeding" reality testify the variety of religious feelings, beliefs and practices. The Authenticity of this feeling is empowered by the narration of personal/subjective experiences. As for answers, the turnover between the social epistemic rhetoric of "closeness" and "openness" testify the efforts to offer responsible answers to the authentic questions, founded in the "classic styles" of the different religious traditions, but empowered through the web reputation dynamics, which offer new spaces for authorship, legitimated authorities (Campbell, 2010) and alternative relevance.

The whole process of participation to these turns can help cyber-believers to identify possible options, and at the same time, to evaluate them, reduce uncertainty and doubt (Bratucu et al., 2014) and empower their religiosity. As a possible parallel way for the religious comprehension, persons can question about both traditional and new topics and find answers, that are socially constructed and validated - through the system of the up/down votes.

The main limits of our work are related to: (a) the heterogeneity of the selected topics. Indeed, even if we chose the most upvoted questions dealing with practices and attitudes, specific argumentation/legitimation strategies could be used in relation to specific issues; (b) in our analysis we did not include the valuation system. It could be useful to comprehend which kinds of answers are more satisfying in relation with both the questioner's needs and the Q\&A community; (c) "comments"- to questions and answers - should be taken into account, since they can facilitate the comprehension of the perceived efficacy and efficiency of the discussions; and (d) even if the selected corpus was composed by about 800 items, a larger number of questions should be included.

Nonetheless, this paper represents a first effort to investigate the role of Q\&A websites in the construction, confirmation and validation of religious feelings, beliefs and practices in accordance with the religious backgrounds. In comparison with other works, more focused on the "top-down" dynamics typical of religious blogs (Campbell, 2010; Whitehead, 2015) and websites (Hill-Smith, 2011), we tried to present some specific features of the Authenticity and responsibility in participation to Q\&A websites, working as systems of knowledge co-construction in several life domains. Indeed, we found a "certain" freedom to ask and answer, which is not an "uncontrolled" freedom, since it is related to the website frames and the web reputation. Our study confirms that, also in the domain of religious experience, Q\&A websites work as models of "aggregate peer authority" (Gazan, 2009). Cyber-believers' participation is improved by the perception of the value of a context where many minds merge to address not only common problems (Gazan, 2011), but also extraordinary matters. Future investigations should first extend the sampling procedure, with the aim to individuate more systematic regularities in the discursive construction of questions and answers, which guarantee virtuosity in social discussion and participation. Second, the qualitative and quantitative analysis of the whole system - question, answer and comments - can offer significant insights both in domain of overcoming possible critical features of Q\&A websites, improving their general reputation, and for those who want empower online lived religions. 


\section{Authors' note}

All authors have agreed to the submission. The article is not currently being considered for publication by any other print or electronic journal.

\section{Acknowledgements}

A special thank is devoted to the research group of the SIR project "Investigating the Role of Emotions in Online Question \& Answering Sites"

\section{Funding}

The author(s) received no financial support for the research, authorship, and/or publication of this article.

\section{ORCID iD}

Rosa Scardigno (iD https://orcid.org/0000-0002-5725-6483

\section{Notes}

1. Data were collected at March 2019

2. At the end of each extract, a letter marks the reference to the specific religious form of life as follows: $\mathrm{C}$ for Christianity, I for Islam, B for Buddhism and $\mathrm{H}$ for Hinduism.

3. In line with other types of "sociolects"- such as the "motherese" and the "politichese"-we defined "religionese" as the micro-language and the religious jargon which are valid for different forms of life as well as for specific groups.

\section{References}

Ajana, B. (2005). (Dis)embodiment and cyberspace: A phenomenological approach. Electronic Journal of Sociology, 7, 1-10.

Allport, G. W., \& Ross, J. M. (1967). Personal religious orientation and prejudice. Journal of Personality and Social Psychology, 5, 432-443.

Anderson, A., Huttenlocher, D., Kleinberg, J., \& Leskovec, J. (2012). Discovering value from community activity on focused question answering sites: A case study of stack overflow. In Proceedings of 18th ACM SIGKDD international conference knowledge discovery data mining (pp. 850-858). https://doi. org/10.1145/2339530.2339665

Barassi, V., \& Treré, E. (2012). Does Web 3.0 come after Web 2.0? Deconstructing theoretical assumptions through practice. New Media \& Society, 14(8), 1269-1285.

Bellah, R. (1970). Beyond belief. Harper \& Row.

Belzen, J. A. (2005). A way out of crisis? From Völkerpsychologie to cultural psychology of religion. Theory and Psychology, 15(6), 812-838.

Belzen, J. A. (2010). Towards cultural psychology of religion: Principles, approaches and applications. Springer.

Berger, H., \& Ezzy, D. (2004). The Internet as virtual spiritual community: Teen witches in the United States and Australia. In L. Dawson \& D. Cowan (Eds.), Religion online: Finding faith on the Internet (pp. 175-188). Routledge.

Berger, P. L. (1967). The sacred canopy: Elements of a sociological theory of religion. Doubleday.

Berlin, J. A. (1993). Post-structuralism, semiotics, and social-epistemic rhetoric: Converging agendas. In T. Enos \& S. Brown (Eds.), Defining the new rhetoric (pp. 137-176). SAGE.

Billig, M. (1987). Arguing and thinking. A rhetorical approach to social psychology. Cambridge University Press.

Bowie, F. (2006). Anthropology of religion. In R. A. Segal (Ed.), The Blackwell companion to the study of religion (pp. 3-24). Blackwell. 
Bratucu, R., Gheorghe, I. R., Purcarea, R. M., Gheorghe, C. M., Popa Velea, O., \& Purcarea, V. L. (2014). Cause and effect: The linkage between the health information seeking behavior and the online environment-A review. Journal of Medicine and Life, 7(3), 310-316.

Caffi, C. (2013). Mitigation. In M. Sbisà \& K. Turner (Eds.), Pragmatics of speech actions (pp. 235-288). De Gruyter.

Campbell, H. A. (2004). Challenges created by online religious networks. Journal of Media and Religion, 3(2), 81-99. https://doi.org/10.1207/s15328415jmr0302_1

Campbell, H. A. (2005). Exploring religious community online: We are one in the network. Peter Lang.

Campbell, H. A. (2010). Religious authority and the blogosphere. Journal of Computer-Mediated Communication, 15(2), 251-276.

Campbell, H. A. (2012). Digital religion: Understanding religious practice in new media worlds. Routledge.

Campbell, H. A. (2013). Religion and the Internet: A microcosm for studying Internet trends and implications. New Media \& Society, 15(5), 680-694. https://doi.org/10.1177/1461444812462848

Cherwitz, R. A., \& Hikins, J. A. (1986). Communication and knowledge: An investigation in rhetorical epistemology. University of South Carolina Press.

Cowan, D. E. (2004). Contested spaces: Movement, countermovement, and e-space propaganda. In L. L. Dawson \& D. E. Cowan (Eds.), Religion online: Finding faith on the Internet (pp. 255-271). Routledge.

Dawson, L. L., \& Cowan, D. E. (2004). Religion online: Finding faith on the Internet. Routledge.

Douglas, M. (1966). Purity and danger. Routledge and Kegan Paul.

Douglas, M. (1970). Natural symbols: Explorations in cosmology (1st ed.). Penguin.

Edwards, D., \& Potter, J. (2005). Discursive psychology, mental states and descriptions. In L. Molder \& J. Potter (Eds.), Conversation and cognition (pp. 241-259). Cambridge University Press.

Fuchs, C. (2008). Internet and society: Social theory in the information age. Routledge.

Gazan, R. (2009). When online communities become self-aware. In Proceedings of the 42nd Hawaii International Conference on System Sciences (HICSS-42) (pp. 1-10). IEEE Computer Society Press.

Gazan, R. (2011). Social Q\&A. Journal of the American Society for Information Science and Technology, 62(12), 2301-2312.

Geertz, C. (1973). The interpretation of cultures. Basic Books.

Geertz, C. (2005). Shifting aims, moving targets: On the anthropology of religion. Journal of Royal Anthropological Institute, 11, 1-15.

Gunther, R., Mughan, A., Bennett, W. L., \& Entman, R. M. (Eds.). (2000). Democracy and the media: A comparative perspective. Cambridge University Press.

Hackett, R. I. J. (2006). Religion and the Internet. Diogenes, 211, 67-76.

Hadden, J. K., \& Cowan, D. E. (2000). Religion on the Internet. JAI Press.

Harré, R., \& Gillet, G. R. (1994). The discursive mind. SAGE.

Helland, C. (2005). Online religion as lived religion: Methodological issues in the study of religious participation on the internet. Online-Heidelberg Journal of Religions on the Internet, 1(1). http://archiv.ub.uniheidelberg.de/volltextserver/volltexte/2005/5823/pdf/Helland3a.pdf

Hermans, H. J. M. (2002). The dialogical self as a society of mind. Theory \& Psychology, 12, 147-160.

Hill-Smith, C. (2011). Cyberpilgrimage: The (virtual) reality of online pilgrimage experience. Religion Compass, 5(6), 236-246. https://doi.org/10.1111/j.1749-8171.2011.00277.x

Hjarvard, S. (2011). The mediatisation of religion: Theorising religion, media and social change. Culture and Religion, 12(2), 119-135. https://doi.org/10.1080/14755610.2011.579719

Hoover, S. M. (2003). Religion, media and identity: Theory and method in audience research on religion and media. In J. Mitchell \& S. Marriage (Eds.), Mediating religion: Studies in media, religion and culture (pp. 9-20). T \& T Clark.

Hsu, I.-C. (2006). Enhancing employee tendencies to share knowledge - Case studies of nine companies in Taiwan. International Journal of Information Management, 26(4), 326-338.

Hutchings, T. (2010). The politics of familiarity: Visual, liturgical and organisational conformity in the online church. Online-Heidelberg Journal of Religions on the Internet, 4.1, 63-86. 
Jan, M. T., Abdullah, K., \& Momen, A. (2015). Factors influencing the adoption of social networking sites: Malaysian Muslim users perspective. Journal of Economics, Business and Management, 3(2), 267-270.

Jennings, T. W. (1982). On ritual knowledge. The Journal of Religion, 62(2), 111-127.

Jin, J., Li, Y., Zhong, X., \& Zhai, L. (2015). Why users contribute knowledge to online communities: An empirical study of an online social Q\&A community. Information \& Management, 52, 840-849.

Joinson, A. N., \& Paine, C. B. (2007). Self-disclosure, privacy and the Internet. In A. Joinson, K. McKenna, T. Postmes, \& U. D. Reips (Eds.), The Oxford handbook of internet psychology (pp. 235-250). Oxford University Press.

Kanthawala, S., Vermeesch, A., Given, B., \& Huh, J. (2016). Answers to health questions: Internet search results versus online health community responses. Journal of Medical Internet Research, 18(4), Article e95.

Lanham, R. A. (2006). The economics of attention: Style and substance in the age of information. University of Chicago Press.

Lee, R. L. M. (2018). Access to excess: Media as religion and the new cargo cults. Culture and Religion, 19(3), 345-360. https://doi.org/10.1080/14755610.2018.1489865

Lindholm, C. (2008). Culture and authenticity. Blackwell.

Lotman, Y. (1984). O semiosfere semeiotike. Sign System Studies, 17, 5-23.

Luckmann, T. (1970). The invisible religion: The problem of religion in modern society. Macmillan.

Manuti, A., Scardigno, R., \& Mininni, G. (2016). Me, myself and God: Religion as a psycho-cultural resource of meaning in later life. Culture \& Psychology, 22(1), 3-34.

Martin-Barbero, J. (1997). Mass Media as a Site of Resacralization of Contemporary Culture. In S. Hoover \& K. Lundby (Eds.), Rethinking media, religion and culture (pp. 102-116). SAGE.

Miller, V. (2009). Consuming religion: Christian faith and practice in a consumer culture. Continuum.

Mininni, G., Manuti, A., Scardigno, R., \& Rubino, R. (2014). Old roots, new branches: The shoots of diatextual analysis. Qualitative Research in Psychology, 11(4), 384-399.

Mininni, G., Scardigno, R., \& Grattagliano, I. (2014). The dialogic construction of certainty in legal contexts. Language \& Dialogue. Special Issue Certainty and Uncertainty in Dialogue, 4(1), 112-131.

Mohammadi, A. S. (2003). Communication and information era in religious globalization. Journal of Research and Deliberation, 35, 147-150.

Morris, M. R., Teevan, J., \& Panovich, K. (2010, April). What do people ask their social networks, and why? A survey study of status message Q\&A behavior [conference session]. In Proceedings of the SIGCHI Conference on Human Factors in Computing Systems (CHI), Atlanta, GA, United States.

O'Leary, S. D. (1996). Cyberspace as sacred space: Communicating religion on computer networks. Journal of the American Academy of Religion, LXIV, 781-808.

O'Reilly, T. (2007). What is Web 2.0: Design patterns and business models for the next generation of software. International Journal of Digital Economics, 65, 17-37.

Orlikowski, W. J. (2000). Using technology and constituting structures: A practice lens for studying technology in organizations. Organization Science, 11(4), 404-428.

Orsi, R. A. (2003). Is the study of lived religion irrelevant to the world we live in? Journal for the Scientific Study of Religion, 42(2), 169-174.

Pace, E. (2008). Raccontare Dio. La religione come comunicazione [Narrating God. Religion as communication]. Il Mulino.

Pace, E. (2013). La comunicazione invisibile. Le religioni in internet [The invisible communication. Religions in the Internet]. San Paolo Edizioni.

Pargament, K. I. (1997). The psychology of religion and coping: Theory, research, practice. Guilford.

Park, C. L. (2010). Making sense of the meaning literature: An integrative review of meaning making and its effects on adjustment to stressful life events. Psychological Bulletin, 136(2), 257-301.

Postill, J. (2010). Introduction: Theorising media and practice. In B. Bräuchler \& J. Postill (Eds.), Theorising media and practice (pp. 1-35). Berghahn.

Radde-Antweiler, K. (2013). Authenticity. In H. Campbell (Ed.), Digital religion: Understanding religious practice in new media world (pp. 88-103). Routledge. 
Riva, G. (2008). Enacting interactivity: The role of presence. Emerging Communication: Studies in New Technologies and Practices in Communication, 10, 97-114.

Scardigno, R., \& Mininni, G. (2013). What is it like to feel good in this world? The several meanings of religious wellbeing. In H. Westerink (Ed.), Constructs of meaning and religious transformation. Current issues in the psychology of religion (pp. 143-165). Unipress.

Scardigno, R., \& Mininni, G. (2014). Rhetorics of (un)certainty in religious discourse. In S. Cantarini, W. Abraham \& E. Leiss (Eds.), Certainty-uncertainty-And the attitudinal space in between (pp. 343362). [SLCS 165] John Benjamin.

Scardigno, R., Pastore, S., \& Mininni, G. (2019). The mixed family as a discursive melting pot of cultures [La famiglia mista come crogiolo discorsivo di culture]. Psicologia Sociale, 14(1), 73-98.

Shah, C., Oh, J. S., \& Oh, S. (2009). Research agenda for social Q\&A. Library \& Information Science Research, 31(4), 205-209.

Sobel, D. L. (2000). The process that "John Doe" is due: Addressing the legal challenge to Internet anonymity. Virginia Journal of Law and Technology, 5. https://heinonline.org/HOL/LandingPage?handle=hein. journals $/$ vjolt $5 \&$ div $=5 \&$ id $=\&$ page $=$

Tan Meng, Y. (2019). Authenticity in online religion: An actor-network approach. In Information Resources Management Association (Ed.), Multigenerational online behavior and media use: Concepts, methodologies, tools, and applications (pp. 540-551). IGI Global. https://doi.org/10.4018/978-1-5225-7909-0. ch029

Taylor, C. (2007). A secular age. Harvard University Press.

Vecoli, F. (2013). La religione ai tempi del Web [Religion at times of Web]. Laterza.

Wang, S., \& Noe, R. A. (2010). Knowledge sharing: A review and directions for future research. Human Resources Management Review, 20(2), 115-131.

Wasko, M. M., \& Faraj, S. (2005). Why should I share? Examining social capital and knowledge contribution in electronic networks of practice. MIS Quarterly, 1, 35-57.

Whitehead, D. (2015). The evidence of things unseen: Authenticity and fraud in the Christian mommy blogosphere. Journal of the American Academy of Religion, 83(1), 120-150. https://doi.org/10.1093/jaarel/ lfu083

Williams, J. P., \& Copes, H. (2005). "How edge are you?" Constructing authentic identities and subcultural boundaries in a straightedge. Internet Forum Symbolic Interaction, 28(1), 67-89.

Wuthnow, R. J. (2011). Taking talk seriously: Religious discourse as social practice. Journal for the Scientific Study of Religion, 50(1), 1-21.

Young, G. (2004). Reading and praying online: The continuity of religion online and online religion in Internet Christianity. In L. Dawson \& D. Cowan (Eds.), Religion online: Finding faith on the Internet (pp. 93-106). Routledge.

Zagaria, A. E., Scardigno, R., Colonna, C., \& Mininni, G. (2018). Discursive dynamics in restructuring parental roles in families with rare disease [Dinamiche discorsive nella ristrutturazione dei ruoli genitoriali in famiglie con malati rari]. Psicologia Della Salute, 2, 70-90.

Zeiler, X. (2019). Introduction: Mediatized religion in Asia. Interrelations of Media, Culture and Society beyond the "West." In K. Radde-Antweiler \& X. Zeiler (Eds.), Mediatized religion in Asia. Studies on digital media and religion (1st ed.) (pp. 3-15). Routledge. 